\title{
Socio-Emotional Cues Can Help 10-Month-Olds Understand the Relationship Between Others' Words and Goals
}

\author{
Youn Mi Cathy Lee ${ }^{1}$, Min Ju Kim², Hyun-joo Song ${ }^{1}$ \\ Department of Psychology, Yonsei University, Seoul, Korea ${ }^{1}$ \\ Department of Psychology, University of California at San Diego, San Diego, United States ${ }^{2}$ \\ 타인의 단어와 행동 목표의 관계성에 대한 10 개월 영아의 이해에 있어서 \\ 사회정서 단서의 영향 \\ 이윤미 ${ }^{1}$, 김민주 ${ }^{2}$, 송현주 $^{1}$ \\ 연세대학교 심리학과 ${ }^{1}$, Department of Psychology, University of California at San Diego ${ }^{2}$
}

Objective: The current study examined whether providing both an actor's eye gaze and emotional expressions can help 10-month-olds interpret a change in the actor's words as a signal to a change in the actor's goal object.

Methods: Sixteen 10-month-olds participated in an experiment using the violation-of-expectation paradigm and were compared to 1610 -month-olds in a control condition. The infants in the experimental condition were familiarized to an event in which an actor looks at one of two novel objects, excitingly utters a sentence, "Wow, here's a modi!", and grasps the object. The procedure in the control condition was identical to that of the experimental condition except that the infants heard the sentence without any emotional excitement and the eye gaze of the agent was hidden by a visor. In the following test trial, the infants in both conditions heard the agent changing her word (from modi to papu) and watched her grasping either the same object as before (old-goal event) or the new object (new-goal event).

Results: The infants in the experimental condition looked at the old-goal event longer than at the new-goal event, suggesting that they expected the agent to change her goal object when the actor changed her word. However, the infants in the control condition looked at the two events about equally.

Conclusion: When both eye gaze and emotional cues were provided, 10-month-olds were able to exploit the agent's verbal information when reasoning about whether the agent would pursue the same goal object as before.

Keywords: infancy, cognitive development, goal understanding, socio-emotional cues, violation-ofexpectation paradigm

\section{서론 \\ 우리는 타인의 행동을 이해하고 예측하는데 있어 그 행동을 \\ Corresponding Author: Hyun-joo Song, Department of Psychology, Yonsei University, 50 Yonsei-ro, Seodaemun-gu, Seoul, Korea \\ E-mail: hsong@yonsei.ac.kr}

둘러싼 여러 정보들을 활용한다. 예를 들어 어떤 친구가 여 러 개의 인형들 가운데 곰돌이 인형을 바라보고 잡는 것을 여 러 번 반복해서 목격하고, 게다가 곰돌이를 보고 “우와, 곰돌

(C)The Korean Association of Child Studies

This is an Open Access article distributed under the terms of the Creative Commons Attribution Non-Commercial License (http:// creativecommons.org/licenses/by-nc/4.0) which permits unrestricted noncommercial use, distribution, and reproduction in any medium, provided the original work is properly cited. 
이다!”라며 좋아하는 감탄사까지 연발한다면 이 친구는 곰돌 이 인형을 좋아한다고 추측할 수 있을 것이다. 또한 토끼 인형 과 곰돌이 인형이 한 곳에 놓여있을 때 이 친구는 둘 중 곰돌이 인형을 잡을 것이라는 예측도 할 수 있을 것이다. 그러나 만약 에 이 친구가 “우와, 토끼다!”라고 외친다면 이번에는 토끼 인 형을 잡을 것이라 예상할 수 있을 것이다. 이와 같이 우리는 타 인의 행동과 다양한 사회적 단서들을 활용하여 타인의 의도를 파악하고 행동 목표를 추측할 수 있다.

생후 일 년 이내의 어린 영아들도 위와 같은 여러 맥락적 단서들을 활용하여 타인의 행동 목표를 이해한다. 첫째, 영 아들은 타인이 한 가지 행동을 여러 번 반복하는 경우(예: 두 물체 중 한 물체를 반복적으로 잡기)와 같은 이전-선택 정보 (prior-choice information)를 활용하여 이후 행동에서의 목표 를 추론한다. 예를 들어 Woodward (1998)는 기대 위배 패러다 임(violation-of-expectation paradigm)을 사용하여 9개월 영아들 의 이전-선택 정보를 활용한 행동 목표 추론을 살펴보았다. 기 대 위배 패러다임은 영아들이 본인의 기대에 위배되는 상황을 접했을 때 이에 대한 일종의 '놀란' 반응으로 해당 상황을 기대 에 부합하는 다른 상황 보다 더 오랜 시간 응시하는 행동 패턴 을 기반으로 하는 연구 방법이다. 이를 활용한 연구에서는 우 선 영아에게 특정한 기대를 형성할 수 있는 사전 정보를 제공 하는 상황을 반복하여 보여준 후(예: 습관화 또는 친숙화 단 계), 영아가 기대할 수 있는 상황 또는 기대에 어긋나는 상황 을 보여주고(예: 검사 단계) 이때의 응시 시간을 측정하여 비 교한다. 즉, 검사 단계에서 두 상황 간 응시 시간에 차이가 있 다는 것은 영아가 사전 정보를 이해하고 이를 바탕으로 특정 한 기대를 형성했음을 추측할 수 있게 한다. 이와 같은 방식을 활용한 Woodward (1998)에서는 9개월 영아들에게 습관화 단 계에서 행위자가 앞에 놓인 두 물체 중 한 물체를 잡는 행동을 여러 번 반복하여 보여주었다. 이후 검사 단계에서는 행위자 가 이전 단계에서 잡았던 물체를 잡는 행동(기존 목표 사건)과 다른 물체를 잡는 행동(새 목표 사건)을 번갈아 보여주었다. 그 결과 영아들은 새 목표 사건을 기존 목표 사건보다 더 오래 응시하였다. 이는 영아들이 행위자가 습관화 단계에서와 동 일한 목표 사물을 취할 것이라고 기대하였고, 이러한 기대에 위반되는 행동(새로운 물체를 잡는 행동)에 놀란 반응으로 응 시 시간이 길어진 것으로 볼 수 있다. 시선 추적 장치를 이용 하여 보기 선호 기법(preferential looking method)으로 살펴본 연구(Cannon \& Woodward, 2012)와 모방하기 과제(imitation procedure)를 사용한 연구(Thoermer, Woodward, Sodian, Perst, $\&$ Kristen, 2013)에서도 이와 같은 반복된 이전-선택 정보를 활
용한 영아들의 타인의 행동 목표 이해가 확인되었다.

둘째, 언어 정보(verbal information) 역시 타인의 목표 행동 에 대한 정보를 제공할 수 있다. 언어를 산출하기 전(preverbal) 의 영아들도 단어의 의미가 같은 언어 사용자 간 서로 공유된 다는 언어의 관습성(conventionality)에 대한 이해가 있으며 물 체의 명칭이 화자 간에 공유된다는 이해를 갖고 있다(Buresh \& Woodward, 2007; Henderson \& Scott, 2015; Lee \& Song, 2016). Buresh와 Woodward (2007)는 영아들이 이러한 언어 정 보를 활용하여 타인의 행동 목표를 도출해 낼 수 있음을 보 여주었다. 먼저 행위자1은 두 물체 중 한 물체를 바라보며 “a modi”라는 새로운 단어를 말하며(명명화 조건) 물체를 잡고 다 시 한 번 “a modi”라고 발화하는 행동을 여러 번 반복해서 보여 주었다. 다음 물체의 위치와 행위자가 바뀌고, 이어지는 검사 시행에서는 행위자2가 나와 동일하게 "a modi"라는 단어를 발 화하며 기존 물체를 잡거나(기존 목표 사건) 다른 물체를 잡았 다(새 목표 사건). 그 결과 13 개월의 영아들은 새 목표 사건을 기존 목표 사건보다 더 오래 응시하였다. 반면 단어 대신 "Ooh, hmm”이라는 소리를 내며 물체를 잡는 장면을 보여준 경우(비 명명화 조건) 두 사건(기존 목표 vs. 새 목표 사건)에 대한 영아 들의 응시 시간에는 차이가 없었다. 즉, 영아들은 “a modi”라는 언어적 단서가 둘 중 한 물체 또는 물체를 잡는 행동을 지칭하 며 따라서 행위자가 바뀌어도 동일한 명칭이 사용된 경우 다 른 행위자(행위자2)도 해당 행동을 할 것이라 기대하는 모습 을 보여주었다. 이와 같이 생후 1 년 전후의 영아들이 언어 정 보가 타인에게 자신의 행동 목표를 알리는 의사소통 기능이 있음을 이해한다는 것은 다른 연구들에서도 반복해서 확인되 었다(e.g., Graham, Stock, \& Henderson, 2006; Martin, Onishi, $\&$ Vouloumanos, 2012).

더 나아가 영아들은 언어 정보의 변화를 인지하고 이를 단 서로 타인의 행동 목표의 변화를 예측할 수 있다(Jin \& Song, 2008; Kim \& Song, 2015; Song, Baillargeon, \& Fisher, 2014). Song 등(2014)에서 다른 단어 조건의 7 개월과 12 개월 영아들 은 우선 친숙화 시행에서 행위자가 “a dax"라는 새로운 단어를 발화하며 두 물체 중 한 물체를 잡는 장면을 반복해서 보았다. 검사 시행에서는 같은 행위자가 “a pilk"라는 다른 단어를 발화 하며 기존과 동일한 물체 또는 다른 물체를 잡는 장면을 보았 다. 반면 통제 조건의 경우 검사 시행에서 행위자는 이전과 동 일한 단어인 “a dax"를 발화하거나, 친숙화 및 검사 시행 모두 에서 어떤 발화도 하지 않은 후 물체를 잡았다. 12 개월의 영아 들은 통제 조건에서는 새로운 물체를 잡는 행동을 기존 물체 를 잡는 행동보다 더 오래 응시하여 이전-선택 정보와 언어 정 
보를 활용하여 행위자의 행동 목표는 이전과 동일할 것이라는 기대가 있음을 나타냈다. 다른 단어 조건의 12 개월 영아들은 두 행동을 비슷하게 응시하였다. 이러한 결과는 영아들이 단 어의 변화를 탐지한 후 행위자가 기존과 동일한 목표 사물을 잡을 것이라는 기대는 취소하였지만, 구체적으로 어떤 행동을 할지에 대한 기대를 형성하지는 못한 것을 제안한다. 반면 7개 월 영아들의 경우 다른 단어 조건과 통제 조건 모두에서 새로 운 목표 행동을 기존 목표 행동보다 더 오래 응시하여 언어 정 보는 고려하지 않고 타인의 행동 목표 사물이 변화하는지에 따라 응시 시간의 변화가 나타나고 있음을 보였다.

Jin과 Song (2008)은 단어 및 행동을 처리할 수 있는 시간 이 좀 더 주어졌을 때 12 개월 영아들이 언어 정보 변화에 따른 타인의 행동 목표 변화를 추론할 수 있음을 보여주었다. Song 등(2014)에서는 친숙화 시행과 검사 시행에서 새로운 단어(a $d a x, \mathrm{a} p i l k)$ 들을 각 두 번 발화한 후 물체를 잡았는데, 첫 단어 발화 시작 시점부터 물체를 잡는 행동이 시작되는 시점 간에 총 4 초의 간격이 있었다. 영아들은 이 4 초의 시간 동안 단어를 듣고 이해한 후 이후 나올 행동에 대해 추론해야했다. 반면 Jin 과 Song (2008)에서는 단어를 각 세 번씩 발화하였으며, 첫 단 어의 발화 시작점과 행위자의 행동 시발점 간에 총 8 초의 시간 을 주어 영아들이 언어 정보를 이해하고 행동을 추론할 수 있 는 시간을 증가시켰다. 이 연구에서 12 개월의 영아들은 검사 시행에서 행위자의 단어가 변화한 후 기존 물체를 잡을 경우, 새로운 물체를 잡을 때보다 더 오래 응시하였다. 이러한 결과 는 처리 시간이 좀 더 충분히 제공된 경우 12 개월 영아들이 언 어 정보의 변화를 활용하여 목표 행동에 변화가 있을 것이라 는 기대를 형성할 수 있음을 보여주었다.

Kim과 Song (2015)은 더 어린 10개월의 영아들도 언어적 단 서의 변화를 활용하여 타인의 행동 목표를 이해할 수 있는지 살펴보았다. 생후 9,10 개월은 언어 정보를 사용하여 개체의 수를 파악하고 범주를 구분할 수 있는 등의 인지적 과제를 수 행할 수 있으며(Balaban \& Waxman, 1997; Dewar \& Xu, 2007; $\mathrm{Xu}, 2002)$, 같은 언어 집단의 사용자 간에는 단어의 의미가 공 유된다는 언어의 관습성에 대한 이해가 나타나는 시기이다 (Buresh \& Woodward, 2007). Kim과 Song (2015)에서는 더 어린 영아들의 경우 단어와 물체의 연결을 학습하는데 있어 더 많 은 반복 경험이 도움이 될 수 있다고 판단하였으며 이에 따른 효과를 확인하기 위해 기존과 동일한 짧은 친숙화 조건(4개의 친숙화 시행)과 긴 친숙화 조건(6개의 친숙화 시행)으로 나누 어 연구를 실시하였다. 친숙화 시행에서 행위자가“모디가 있 네!”라는 문장을 두 번 발화하고 두 물체 중 한 물체를 잡는 장
면을 반복하여 보여준 후, 검사 시행에서는 “파푸가 있네!”라 는 문장을 두 번 발화하고 기존과 동일한 물체를 잡는 행동과 새로운 물체를 잡는 행동을 번갈아 보여주었다. 이 결과 짧은 친숙화 조건의 영아들은 새로운 물체를 잡는 행동을 기존 물 체를 잡는 행동보다 더 오래 응시하였다. 이는 짧은 친숙화 조 건의 10 개월 영아들이 언어적 단서의 변화에 따른 목표 행동 변화를 기대하지 않았음을 보여주며, 이러한 결과는 Song 등 (2014)에서 7개월 영아가 보인 결과와 유사하다. 반면 긴 친숙 화 조건의 10 개월 영아들은 새로운 물체를 잡는 행동과 기존 물체를 잡는 행동을 비슷하게 오래 응시하였고, 이러한 결과 는 Song 등(2014)의 12 개월 영아들이 보인 결과와 유사하였다. 이는 긴 친숙화 조건의 10 개월 영아들 역시 언어적 단서의 변 화가 있을 경우 이를 탐지하고, 행위자의 목표가 기존 사건과 동일할 것이라는 기대는 취소하지만, 행동이 어떤 특정한 목 표로 바뀔 것인지에 대한 구체적인 기대를 형성하지는 못했음 을 보여준다.

본 연구는 Kim과 Song (2015)의 연구 패러다임을 수정하여 추가적인 단서들이 제공될 경우에는 만 10 개월의 영아들이 언어 정보의 변화가 행동 목표의 변화로 이루어 질 수 있다는 구체적인 기대를 형성할 수 있는지 알아보고자 하였다. 추가 적인 단서들로는 시선 및 정서 표현 단서가 사용되었다.

영아들은 생애 초기부터 타인의 시선에 민감하다. 신생아 들도 타인의 시선이 향하는 방향에 주의를 기울이는 경향을 보이고(Haith, Bergman, \& Moore, 1977), 6개월경에는 타인이 바라보는 시선의 방향을 따라 응시하는 모습을 보인다(Brooks \& Meltzoff, 2005; Farroni, Csibra, Simion, \& Johnson, 2002). 그 리고 8-10개월 정도부터 시선의 목표 지향성 및 사회적 의미 를 어느 정도 이해하는 것으로 보인다. 10 개월 영아들은 어떤 사람이 대화를 하는듯한 발화를 하면서 보이지 않는 스크린 뒤쪽을 바라볼 경우, 스크린 뒤에 사람이 있을 것이라고 기대 를 하며, 사람이 아닌 물체(예: 장난감 트랙터)가 있을 경우에 는 응시 시간이 길어진다(Beier \& Spelke, 2012). 8-9개월 영아 들은 적절한 맥락적 정보가 주어지는 상황(예: 한 각도가 아니 라 여러 가지 각도에서 쳐다봄으로써 행동의 의도성을 부각시 킴)에서는 시선의 목표 사물에 선택적 주의를 기울이고, 시선 의 목표 사물이 변경되었을 때 응시 시간이 길어진다(Johnson, Ok, \& Luo, 2007).

정서 표현에 대해서도 영아들은 민감하게 반응을 보인다. 영아들은 긍정적인 정서 표현을 다른 정서 표현보다 더 선호 하고(e.g., Cooper \& Aslin, 1990; D’Entremont \& Muir, 1999; Singh, Morgan, \& Best, 2002), 이를 괜찮다는(alright) 의미로 이 
해하며(e.g., Sorce, Emde, Campos, \& Klinnert, 1985; Walden \& Ogan, 1988), 긍정적인 반응이 나타난 자극에 더 관심을 보이 는 경향(Hornik, Risenhoover, \& Gunnar, 1987)이 있다.

선행 연구들은 시선과 더불어 긍정적인 감정 표현(표정 및 언어 표현)이 같이 제공될 경우 영아들이 이를 활용하여 타인 의 다른 유형의 행동(예: 잡기) 목표를 추론함을 보여주었다. 예를 들어 Phillips, Wellman과 Spelke (2002)에서 영아들은 행 위자가 두 개의 고양이 인형(예: 주황색 고양이 인형 vs. 회색 고양이 인형) 중 한 가지 인형(예: 주황색 고양이 인형)에 대해 고개를 돌려 쳐다보면서 매우 긍정적인 감정을 나타내는 어조 로 “Oo-oo, look at the kitty."라고 말하는 장면을 반복하여 보았 다. 영아들은 행위자가 주황색 고양이 인형을 잡을 것이라 기 대하는 응시 패턴을 보였다. 주어진 두 개의 물체가 같은 범주 에 속한 경우(예: 주황색 덤프트럭 vs. 빨간색 견인트럭) 영아 들은 이 중 하나의 특정 물체를 행위자의 행동 목표로 이해하 는 것에 어려움을 겪는데(Spaepen \& Spelke, 2007), Phillips 등 (2002)의 결과는 시선 및 정서 표현 정보가 수반될 경우에는 영아들이 행위자의 목표가 같은 범주내의 특정한 물체임을 좀 더 쉽게 이해할 수 있도록 도와줄 수 있음을 보인다. 이러한 선 행 결과는 시선 및 정서 표현과 같은 사회적 단서들이 함께 제 공될 경우 영아들이 이를 활용하여 타인의 행동 목표를 이해 할 수 있음을 보여준다.

따라서 본 연구에서는 Kim과 Song (2015)의 연구 패러다임 에 시선 및 정서 표현과 같은 타인의 목표에 대한 다양한 정보 를 추가적으로 제시하였을 때, 만 10 개월의 영아들이 타인의 언어 변화와 행동 목표의 변화 간의 관계를 추론할 수 있는지 살펴보고자 하였다. 시선과 정서 표현을 함께 제시한 이유는 풍부한 정보가 주어진 최적의 상황에서 영아들의 능력을 검증 해보는 것이 우선적으로 필요하다고 판단되었기 때문이다. 본 연구에서 실험 조건의 친숙화 시행에서는 행위자가 두 물체 중 한 물체를 향해 고개를 돌려 시선을 향하게 하고, 긍정적인 어조로 “우와, 모디가 있네!”와 같은 발화를 한 후 물체를 잡도 록 하였다. 친숙화 시행 이후 두 물체의 위치를 바꾸었고, 검사 시행에서는 행위자가 친숙화 시행과 동일한 물체(기존 목표 사건)나 다른 물체(새 목표 사건)를 쳐다보며 “우와, 파푸가 있 네!”라고 발화한 뒤 해당 물체를 잡았다. 통제 조건의 경우 행 위자가 시선을 가릴 수 있는 챙이 달린 모자(visor)를 쓰고 중 립적인 어조로 발화를 했으며 '우와'를 '봐봐'와 같은 중립적인 표현으로 대체하였다. 이를 제외하면 통제 조건의 절차는 실 험 조건과 동일하였다. 연구가설 및 연구문제는 다음과 같다.

본 연구에서는 시선 단서와 감정 단서가 만 10 개월의 영아
들이 언어적 단서와 목표 행동 간의 관계성을 이해하는데 도 움을 줄 것이라 예측하였다. 따라서 영아들이 행위자의 변화 한 언어 정보(i.e., 단어)가 목표 행동의 변화를 의미함을 이해 하여, 행위자가 검사 시행에서 친숙화 시행과 다른 단어를 발 화한 경우 새로운 물체를 잡는 사건(새 목표 사건)보다 친숙화 시행에서 잡았던 물체를 잡는 사건(기존 목표 사건)을 더 오래 응시할 것이라 예상된다.

\section{연구문제}

만 10 개월의 영아들은 시선 및 감정 단서를 활용하여 타인의 언어적 단서와 목표 행동 간의 관계성을 이해할 수 있는가?

\section{연구방법}

\section{연구대상}

본 연구에는 만 10 개월 영아(평균: 9 개월 30 일, 범위: 8 개월 30 일 10 개월 29일) 48 명(남아 25명, 여아 23명)이 참여하였다. 이 중 연구 도중 울어서 끝까지 진행하지 못했거나(8명), 검사 단계에서 울거나 짜증낸 경우(5명), 또한 응시시간을 측정한 두 명의 관찰자 간의 신뢰도가 낮은 경우(2명)와 아이가 연구 도중 자극 물체를 잡은(1명) 경우는 분석에서 제외되어 최종 연구대상은 32 명이었다. 이들은 실험 조건(평균: 10 개월 2일, 범위: 9개월 1일 10 개월 28일, 남아 8 명, 여아 8 명) 또는 통제 조건(평균: 9 개월 24일, 범위: 8 개월 30 일 10 개월 18 일, 남아 6명, 여아 10명)에 무선 할당되었다. 참가자는 홈페이지나 육 아관련 카페를 통한 홍보로 모집되었으며, 참가 영아와 보호 자에게는 감사의 의미로 간단한 기질검사와 동화책 1 권이 제 공되었다.

\section{연구도구}

연구에는 총 두 개의 비친숙 물체가 사용되었다. 첫 번째 물체 는 가로 $9 \mathrm{~cm}$, 세로 $8.5 \mathrm{~cm}$, 높이 $8.5 \mathrm{~cm}$ 의 직육면체 형태의 상자 로 파란색 바탕에 노란색 줄무늬가 그려져 있었다. 다른 한 물 체는 X자 형태의 스틱 각 끝에 네 개의 작은 구가 붙어있는 형 태로 가로 $8.8 \mathrm{~cm}$, 긴 쪽 세로 $9 \mathrm{~cm}$, 짧은 쪽 세로 $7 \mathrm{~cm}$, 높이 $4 \mathrm{~cm}$ 의 주황색 플라스틱 물체였다. 두 물체는 색상이나 형태에서 뚜렷하게 차이가 나타났다. 
연구는 나무 재질의 너비 $95 \mathrm{~cm}$, 깊이 $64 \mathrm{~cm}$, 높이 $200 \mathrm{~cm}$ 인 아이보리색 무대 장치에서 진행되었다. 이 무대 장치의 정면 에 가로 $88 \mathrm{~cm}$, 높이 $53 \mathrm{~cm}$ 의 흰색 열린 공간(opening)이 바닥에 서 $75 \mathrm{~cm}$ 높이에 위치했다. 이 공간 앞쪽에는 가로 $88 \mathrm{~cm}$, 높이 $57 \mathrm{~cm}$ 의 흰색 스크린이 매 시행의 시작 시 올라가고 종료 시 내려와 시행과 시행 사이에 무대를 완전히 가리도록 하였다. 열린 공간의 무대 양쪽 옆 벽면은 흰색 광목천으로 가려져 있 었으며, 무대 후면에는 무대 오른쪽 끝에서 $5 \mathrm{~cm}$ 떨어진 위치 에 가로 $46 \mathrm{~cm}$, 높이 $50 \mathrm{~cm}$ 의 창문이 뚫려있어 행위자가 의자 에 앉은 상태에서 상반신과 머리가 보이도록 하였다. 행위자 의 뒤쪽은 가로 $1.5 \mathrm{~m}$, 세로 $1.5 \mathrm{~m}$ 의 흰색 스크린으로 가려져 있 었고 무대 장치 안쪽에는 세 개의 형광등 $(20 \mathrm{~W})$ 이 설치되어 흰 색 바탕의 무대에 밝은 조명으로 물체와 행위자의 행동이 명 확하게 보이도록 하였다. 행위자 앞으로 위치한 무대의 열린 공간에 무대 정면에서 $21.5 \mathrm{~cm}$, 우측에서 $12.8 \mathrm{~cm}$ 위치에 한 개 의 물체가 놓였고 이 물체의 정 중앙에서 좌측으로 $27 \mathrm{~cm}$ 떨어 진 곳에 다른 물체의 정 중앙이 위치하도록 두 물체가 나란히 놓였다.

행위자는 파란색 $\mathrm{V}$ 넥 긴팔 티셔츠를 입고 통제 조건에서 만 흰색 챙이 달린 모자를 착용하여 행위자의 시선을 가리도 록 하였다. 무대 장치 양 옆에는 가로 $70 \mathrm{~cm}$, 높이 $180 \mathrm{~cm}$ 의 날 개 형태의 초록색 스크린이 달려있어 두 명의 관찰자가 각 스 크린 뒤에서 무대로부터 $23 \mathrm{~cm}$, 바닥에서 $90 \mathrm{~cm}$ 떨어진 곳에 위치한 지름 $2.5 \mathrm{~cm}$ 의 구멍으로 영아의 시선과 행동을 관찰하 도록 하였다. 무대 장치 정면에는 바닥에서 $63 \mathrm{~cm}$ 높이에 가로 $7 \mathrm{~cm}$, 높이 $10 \mathrm{~cm}$ 의 직사각형 창문이 뚫어져 있어 이 뒤에 캠코 더를 설치하고 창문을 망사로 덧대어 카메라가 정면에서 눈에 띄지 않게 하였다. 이 캠코더는 연구가 진행되는 동안 영아의 모습을 녹화하였다.

\section{연구절차}

연구 시작 전 보호자는 대기실에서 연구에 대한 설명과 주의 사항을 듣고 동의서에 서명을 하였다. 보호자는 연구가 진행 되는 동안 영아의 시선 및 주의집중에 영향을 미칠 수 있으므 로 눈을 감고 말을 삼가도록 하여 영아와의 상호작용을 최소 화 하도록 안내되었다. 안내가 진행되는 동안 영아는 낮선 환 경에 적응할 수 있도록 보조 연구자와 장난감을 갖고 자유롭 게 놀도록 하였다. 모든 준비를 마친 후 실험실에 영아와 보 호자 한 명이 함께 들어갔으며, 무대 장치 정면으로부터 약 $45 \mathrm{~cm}$ 떨어진 위치에 영아가 보호자 무릎에 정면을 바라보고
앉도록 하였다. 연구 시작 직전 행위자는 무대 옆쪽으로 나와 영아에게 인사를 하고 티셔츠 색상 소개와 손에는 아무것도 없음을 확인시켜주었다(예: "이것 봐. 선생님은 파란색 티셔츠 를 입고 있고, 손에는 아무것도 없어.”). 통제 조건에서는 행위 자가 쓰고 있는 챙이 달린 모자도 동일한 방식으로 소개하였 다(예: “선생님은 흰색 모자를 썼어.”).

무대 장치의 양쪽 날개(스크린) 뒤쪽에서는 두 명의 관찰자 가 각각 작은 원형의 구멍을 통해 영아의 시선과 행동을 관찰 하였다. 관찰자들은 컴퓨터에 연결된 조이스틱을 사용하여 영 아가 무대 정면을 바라보는 경우 버튼을 눌러 응시 시간을 측 정하였고, 이는 컴퓨터 프로그램을 통해 실시간으로 기록되었 다. 각 시행은 영아가 무대 정면을 최소 2초 이상 응시한 후 다 른 곳을 연속 2 초 이상 응시하거나, 무대 정면을 누적 60 초 이 상 응시한 경우 자동으로 종료되었다. 이는 영아의 오른쪽에 위치한 주 관찰자(primary observer)의 측정을 기준으로 결정되 었다. 분석에 포함된 참가자 중 두 명은 한 명의 관찰자(주 관 찰자)로 측정되었다. 관찰자들 간의 평균 일치도는 $92 \%$ 였다.

본 연구의 시행은 Kim과 Song (2015)의 긴 친숙화 조건의 구성과 유사하게 진행되었다. 연구 진행 시 행위자의 행동과 대사가 일관되도록 초 단위로 대본(script)을 구성하였으며, 실 제 연구 상황에서 메트로놈을 사용하여 행위자가 초에 맞춰 정확하게 수행할 수 있도록 하였다. Figure 1과 Figure 2는 실험 조건과 통제 조건의 연구 장면 예시를 보여준다. 연구에서 사 용된 두 개의 자극 물체(파란색 상자와 주황색 물체)의 위치 (오른쪽 또는 왼쪽)와 역할(기존 목표 또는 새 목표)은 역균형 화 되었다. 다음은 각 시행 별 자세한 절차이며 괄호 안에 행동 별 수행 시간(초)이 표시되어있다.

\section{실험 조건}

연구는 총 6 개의 친숙화 시행, 1 개의 검사 전 진열 시행, 그리 고 1 개의 검사 시행 순으로 구성되었다.

\section{친숙화 시행}

친숙화 시행 시 무대 오른쪽에는 파란색 상자, 왼쪽에는 주황 색 물체가 지정된 위치에 놓였고, 행위자는 오른손을 두 물체 의 중앙에서 뒤로 $15 \mathrm{~cm}$ 떨어진 지점에 올려둔 상태에서 시행 이 시작되었다. 스크린이 올라가면 행위자는 두 물체 사이의 중앙점을 응시하다(2초), 오른쪽으로 고개를 돌려 파란색 상 자를 쳐다보고(1초), 일상 대화보다 약간 높은 톤과 신나는 듯 

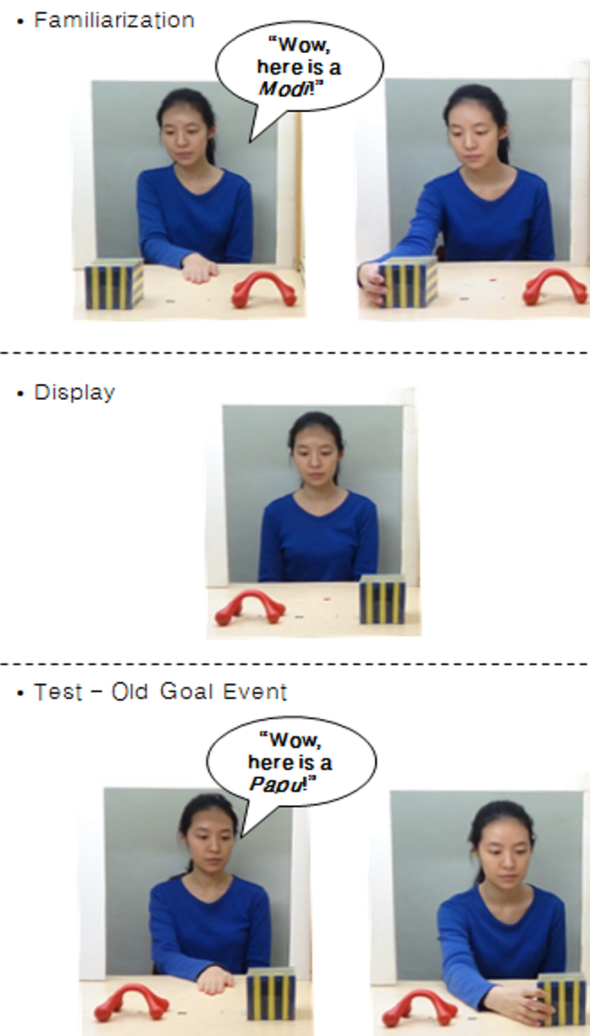

- Test - New Goal Event

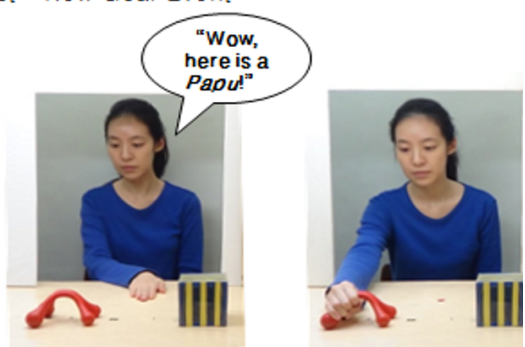

Figure 1. Example of the trials in the experimental condition.

한 목소리로 긍정적인 감정을 나타내며 “우와, 모디가 있네!” 라고 발화한 뒤(4초), 잠시 쉬고(1초), 다시 한 번 동일한 톤으 로 “우와, 모디가 있네!”라는 언어적 단서를 반복하였다(4초). 다음 잠시 쉬었다가(1초), 오른손을 앞으로 뻗어 파란색 상자 를 잡은(1초) 후 이대로 정지하여 시행이 종료될 때까지 유지 하였다. 동작을 정지한 시점부터 주 시행이 시작되었다. 친숙 화 시행은 총 6 번 반복되었다.

\section{검사 전 진열 시행}

검사 전 진열 시행에서는 파란색 상자를 무대의 왼쪽, 주황색
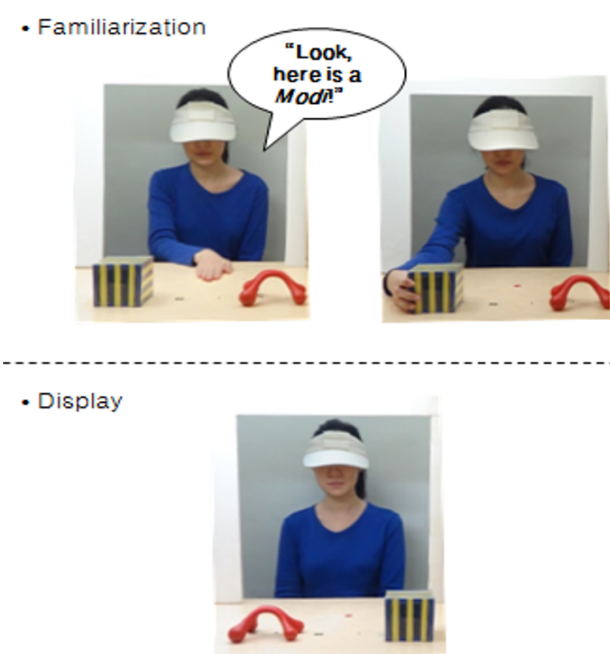

- Test - Old Goal Event

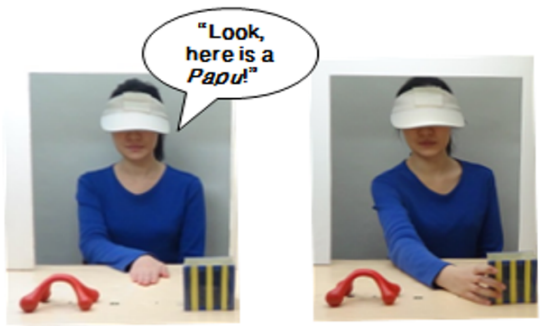

- Test - New Goal Event

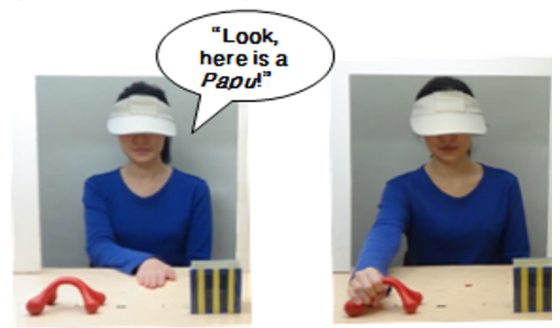

Figure 2. Example of the trials in the control condition.

물체를 오른쪽 지정된 위치로 서로 바꾸어 놓았고, 행위자는 무릎에 손을 올린 채로 두 물체 사이의 중앙점을 응시하며 정 지해 있었다. 무대의 막이 올라간 시점부터 주 시행이 시작되 었으며, 검사 전 진열 시행은 총 1 회 시행되었다.

\section{검사 시행}

검사 시행에서 두 물체의 위치는 앞서 실시했던 검사 전 진열 시행과 동일하였고, 행위자의 오른손은 친숙화 단계에서와 같 은 자세로 두 물체 중앙 $15 \mathrm{~cm}$ 뒤에 놓아둔 채 시작 되었다. 검 사 시행은 행위자가 친숙화 시행과 같은 물체를 잡는 '기존 목 
표 사건'과 다른 물체를 잡는 '새 목표 사건' 두 가지로 구성되 었으며, 영아는 두 사건 중 한 사건에 무선 할당되어 해당 장면 을 보았다. 기존 목표 사건에서 행위자는 두 물체 사이의 중앙 점을 응시하다(2초), 왼쪽으로 고개를 돌려 파란색 상자를 쳐 다보고(1초), 친숙화 단계에서 언어적 단서를 발화할 때와 같 은 톤으로 “우와, 파푸가 있네!”라고 발화한 뒤(4초) 잠시 쉬었 다(1초) 다시 한 번 동일하게 “우와, 파푸가 있네!”를 반복하였 다(4초). 이후 다시 한 번 쉬고(1초) 오른손으로 파란색 상자를 잡고(1초) 정지하였다. 행위자는 이 동작을 시행이 종료될 때 까지 유지하였으며, 정지한 시점부터 주 시행이 시작되었다. 새 목표 사건은 기존 목표 사건과 거의 동일하였으나 오른쪽 으로 고개를 돌려 주황색 물체를 쳐다보고, 오른손으로 주황 색 물체를 잡았다. 영아는 본인이 할당된 조건의 검사 시행 장 면을 1 회 보았다.

\section{통제 조건}

통제 조건에서는 행위자가 챙이 달린 모자를 착용하여 시선 단서를 차단하고 고개를 돌려 물체를 쳐다보는 행동도 하지 않았다. 또한 친숙화 시행과 검사 시행에서 언어적 단서 발화 시 “우와!”라는 감탄사 대신 “봐봐, 모디(또는 파푸)가 있네!”라 고 말하였다. 이때 행위자의 목소리는 특정한 감정을 드러내 지 않은 채 자연스럽게 발화하도록 하였다. 이 외 모든 시행의 순서와 세부 절차는 실험 조건과 동일하였다.

\section{예비 분석}

영아의 성별과 목표 물체의 종류(파란 상자 또는 주황색 물체) 가 검사 시행의 조건이나 사건과 상호작용 하는지 알아보기 위해 사전 분석(preliminary analysis)을 실시한 결과 유의미한 상호작용이 나타나지 않았다, $F_{\mathrm{S}}<1$. 따라서 이후의 분석에서 는 성별과 목표 물체의 종류는 제외되었다.

\section{연구결과}

\section{친숙화 시행}

총 6회의 친숙화 시행 동안의 평균 응시 시간에 대해 조건(실 험 조건 vs. 통제 조건)을 참가자 간 변인으로 일변량 분산 분 석을 실시한 결과 주 효과는 유의미하지 않았다, $F(1,30)=.11$, $p=.75$. 즉 친숙화 시행에서 실험 조건의 영아들 $(M=18.18$, $S D=7.89)$ 과 통제 조건의 영아들 $(M=17.40, S D=5.46)$ 의 평 균 응시 시간 간에는 유의미한 차이가 없음을 보여준다.

\section{검사 전 진열 시행}

검사 전 진열 시행에서의 응시 시간도 친숙화 시행과 동일한 방식으로 분석을 하였다. 그 결과 실험 조건 $(M=9.39, S D=$ 4.62)과 통제 조건 $(M=10.35, S D=6.84)$ 의 응시 시간에는 주 효 과가 나타나지 않았다, $F(1,30)=.21, p=.65$. 따라서 두 조건 간 검사 전 진열 시행을 바라본 시간에 유의미한 차이는 없었다.

\section{검사 시행}

검사 시행의 응시 시간은 조건(실험 조건 vs. 통제 조건)과 사 건(기존 목표 사건 vs. 새 목표 사건)을 참가자 간 변인으로 이 원 분산 분석을 실시한 결과, 조건 $(F[1,28]=.19, p=.66)$ 과 사 건 $(F[1,28]=.94, p=.34)$ 의 주 효과는 모두 유의미하지 않았 다. 그러나 이 두 변인 간의 상호작용은 유의미하였다, $F(1,28)$ $=5.79, p=.02$. Figure 3 은 조건 및 사건에 따른 검사 시행에서 의 영아들의 평균 응시 시간을 나타낸다.

계획 비교(planned comparison) 분석을 통해 각 조건에서 사 건 간(기존 목표 사건 vs. 새 목표 사건)의 응시 시간 차이를 분 석한 결과, 실험 조건의 영아들은 기존 목표 사건 $(M=16.16$, $S D=6.92)$ 을 새 목표 사건 $(M=7.50, S D=2.19)$ 보다 더 오래 응시하였으며 차이는 유의미하였다, $F(1,28)=5.65, p=.02$. 반면 통제 조건의 두 사건 간 응시 시간(기존 목표 사건: $M=$

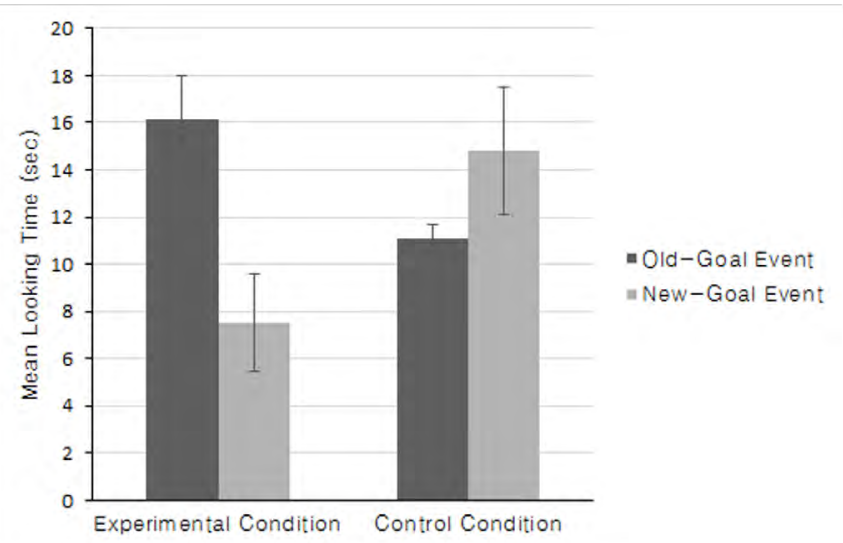

Figure 3. Mean looking times of old-goal and new-goal test events for the infants in the experimental and control conditions. 
$11.11, S D=7.68$; 새 목표 사건: $M=14.80, S D=10.17$ )에는 유 의미한 차이가 나타나지 않았다, $F(1,28)=1.04, p=.32$. 비모 수 Wilcoxon 순위 합계 검정(non-parametric Wilcoxon rank-sum test) 결과에서도 실험 조건 내 사건 간에는 유의미한 차이가 나타난 반면(W $=48.50, p<.01)$, 통제 조건에서는 사건 간 유 의미한 차이가 나타나지 않아 $(\mathrm{W}=59.00, p=.38)$ 동일한 패턴 이 나타났다.

마지막으로 영아들의 응시 시간의 개인차에 따른 영향을 확 인하기 위해 친숙화 시행에서의 평균 응시 시간과 검사 전 진열 시행에서의 응시 시간을 공변인으로 공분산 분석(ANCOVA)을 실시하였다. 분석 결과는 위에서 제시된 이원 분산 분석 결과와 동일하였다. 조건 $(F[1,26]=.20, p=.66)$ 과 사건 $(F[1,26]=.85, p$ $=.37)$ 의 주 효과는 유의미 하지 않았으나 두 변인 간의 상호작 용은 유의미하였다, $F(1,26)=5.62, p=.03$.

\section{논의 및 결론}

본 연구는 만 10 개월 영아들이 시선 및 감정 표현과 같은 사회 정서 단서를 활용하여 언어적 정보의 변화가 타인의 목표 행 동의 변화를 의미한다는 이해를 추론할 수 있는지 살펴보았 다. 영아들은 행위자가 두 물체 중 한 물체를 바라보며 “우와, 모디가 있네!”라고 발화한 뒤 해당 물체를 잡는 장면을 반복 하여 바라본 후, 검사 시행에서는 “우와, 파푸가 있네!”와 같이 다른 단어를 발화한 후 기존에 잡았던 물체 또는 새로운 물체 를 잡는 사건을 보았다. 영아들은 기존 목표 물체를 잡는 사건 을 새 목표 물체를 잡는 사건보다 더 오래 응시하였다. 즉, 만 10 개월의 영아들은 시선 및 감정적 표현 등의 사회적 단서가 주어진 경우 언어 정보가 변화될 때 행위자의 행동 목표가 변 화함을 기대하였고, 이러한 기대가 위배되는 상황(단어가 바 뀌었음에도 불구하고 기존과 동일한 물체를 잡는 상황)을 이 상하게 여겨 응시 시간이 길어짐을 보였다. 반면, 동일한 상황 에서 행위자의 시선 및 감정 단서가 제외된 통제 집단의 경우 두 사건 간 응시 시간에는 유의미한 차이가 나타나지 않았다.

기존 연구에서는 타인의 언어적 단서의 변화와 목표 행동 을 연합하여 타인의 의도를 이해하는 능력은 언어 정보를 처 리할 수 있는 충분한 시간이 제공된 만 12 개월의 영아들에게 서 나타났으며(Jin \& Song, 2008), 이후 Kim과 Song (2015)에서 는 만 10 개월의 영아들도 12 개월 영아들보다 더 많은 개수의 친숙화 시행을 경험하는 경우 언어적 단서의 변화를 지각하는 모습이 나타났다. 하지만 목표 사건과 새 목표 사건 간 응시 시
간에는 유의미한 차이가 나타나지 않아 만 10 개월의 영아들 이 언어 정보의 변화를 타인의 목표 행동의 변화에 대한 신호 로 이해하고 있는지는 알 수 없다는 한계점이 있었다. 이에 본 연구는 시선 단서와 감정 단서와 같은 사회 정서적 정보를 추 가적으로 제공한 경우 동일한 연령의 영아들도 언어적 정보의 변화와 타인의 행동 목표 간의 관계성을 이해할 수 있는지 알 아보고자 하였다.

생후 1 년 이전의 영아들은 이미 타인의 시선의 움직임과 정 서적 표현에 민감하며 이들이 타인의 의도를 내포하고 있음 을 인지하고 있음이 여러 선행 연구들을 통해 확인되었다(e.g., Beier \& Spelke, 2012; Johnson et al., 2007; Luo, 2010; Phillips et al., 2002; Spaepen \& Spelke, 2007). 따라서 본 연구에서는 기존 연구에서 제한하였던 시선 단서를 제공하여 행위자가 해당 물 체를 명확히 응시하였고, “우와!”라는 감탄사와 신나는 듯한 (excited) 목소리 톤으로 긍정적 정서를 함께 표현하도록 하였 다. 그 결과 언어적 단서만 제공될 때와는 달리 만 10 개월의 영아들도 행위자의 의도를 파악하여 변화된 단어가 목표 행동 의 변화를 신호하고 있음을 구체적으로 이해함을 알 수 있었 다.

이러한 본 연구의 결과는 만 10 개월의 영아들이 여러 가지 사회적 단서들을 통합하여 맥락에 적절하게 활용하여 타인의 의도를 이해하는데 활용하고 있음을 추측케 하였다. 만약 영 아들이 맥락에 대한 이해가 없이 시선과 정서적 표현의 목표 지향성만을 이해하였다면 행위자가 친숙화 시행에서 반복하 여 바라보고 긍정적인 정서를 표현한 기존 물체에 대한 선호 또는 행동 목표를 갖고 있다고 예측하여 검사 시행에서 새로 운 물체를 잡은 새 목표 사건을 기존 목표 사건보다 더 오래 응 시하였을 것이다. 그러나 본 연구의 검사 시행에서 행위자는 시선 및 감정적 정보와 함께 변화된 명칭(i.e., 언어적 정보; 모 디 ·파푸)을 제공하였고 영아들은 이에 검사 시행에서 행위자 의 '파푸'라는 언어적 단서가 친숙화 시행에서 '모디'라는 명칭 이 연결(mapping) 되었던 기존 물체가 아닌 새로운 물체를 지 칭하고, 따라서 새로운 물체를 잡으려는 의도가 있을 것이라 는 구체적인 기대를 하는 모습을 보였다. 즉, 본 연구의 영아들 은 시선과 정서적 표현 단서를 행위자의 언어적인 정보와 결 합하여 타인의 의도를 맥락에 적절하게 추론하는 모습을 나타 내었다. 따라서 본 연구의 결과는 시선 및 감정적 정보가 단어 와 지시하는 대상 간의 연결성을 보다 수월하게 이해할 수 있 게 하여 언어적 정보의 변화가 행위자의 향후 행동이 어떻게 변화할 것인지를 추론하는데 도움을 주었다고 추정할 수 있게 한다. 기존 연구들에 의하면 영유아들은 새로운 단어를 학습 
할 때 시선, 가리키기, 감정 표현 등의 사회적 단서들을 활용하 여 새로운 명칭과 지시 대상을 연합시켜 이해한다(e.g., Baldwin et al., 1996; Carpenter, Nagell, Tomasello, Butterworth, \& Moore, 1998; Caza \& Knott, 2012; Grassmann \& Tomasello, 2010; Meyer \& Baldwin, 2013; Moses, Baldwin, Rosicky, \& Tidball, 2001; Sullivan \& Barner, 2016; Tomasello, Strosberg, \& Akhtar, 1996). 특히 본 연구 대상과 같은 만 1세 이전 영아들은 대화적 맥 락이나(Sullivan \& Barner, 2016), 통사적 자동처리(syntactic bootstrapping; Gleitman, 1990) 등을 통해 추론하는 능력이 미숙 하므로 이러한 사회적 단서는 새로운 단어와 지시 대상의 연 결성을 이해하는데 도움을 주어 타인의 의사소통 의도를 파악 하는 과정이 좀 더 용이하게 이루어지도록 할 수 있다.

본 연구에서는 시선 단서를 제공하는데 있어 행위자가 무 대의 정면 중앙과 발화의 대상 물체만 바라보도록 하여 영아 와의 직접적인 눈맞춤은 제외하였다. 기존 연구들에 의하면 영아들은 눈맞춤에 민감하며(Csibra, 2003; Farroni et al., 2002), 타인과 눈맞춤을 한 후 그 사람의 시선을 따라 동일한 물체를 쳐다보는 모습을 보이고(Butterworth \& Jarrett, 1991), 생후 1-5 일 경의 신생아들도 자신과 직접적인 눈맞춤을 하는 얼굴을 시선을 회피하는 얼굴보다 선호하는 모습을 보였다(Farroni et al., 2002). 이와 같이 행위자와 영아 간 직접적인 눈맞춤이 있 는 시선 정보의 제공은 언어 정보와 목표 행동의 관계성에 대 한 이해를 보다 수월하게 할 수 있을 것으로 예상된다. 이는 향 후 연구를 통해 검증해 볼 수 있을 것으로 기대된다.

본 연구에서는 시선 및 감정 단서를 모두 제공한 경우만 살 펴보았다. 이는 다양한 단서로 인해 풍부한 정보가 있는 상황 에서 영아들이 언어 정보의 변화가 목표 사물의 변화에 대한 신호임을 이해할 수 있는지 우선 확증하고자 한 책략적 접근 이었다. 추후 연구에서는 시선 단서와 감정 단서를 분리하여 각각의 지각적 단서가 언어적 정보를 해석하는데 어떠한 영향 을 미치는지 살펴볼 필요가 있다.

본 연구는 만 10 개월의 영아들이 시선 단서와 긍정적 감정 단서를 활용하여 언어적 단서의 변화를 탐지하고, 이에 따른 타인의 목표 행동의 변화를 보다 구체적으로 추론할 수 있음 을 보여 주었다. 만 10 개월의 영아들은 언어적 변화를 탐지 했 음에도 이를 활용하여 타인의 의도에 대한 구체적인 기대를 형성하는데 어려움을 보였지만(Kim \& Song, 2015), 시선 정보 와 정서적 표현과 같은 사회적 단서가 추가적으로 제공되었을 때는 언어 변화가 타인 행동 목표의 변화에 대한 신호임을 이 해하는 것으로 보였다. 이는 시선 및 정서 표현 정보가 언어적 정보와 목표 행동의 관계성에 대한 이해 능력을 향상시킴을
보여준다. 본 연구는 사회적 단서가 단어와 지시하는 대상 간 의 관계에 대한 촉진을 할 수 있는 가능성을 제시하여 언어 학 습에 있어서의 사회적 정보의 영향에 대한 함의점을 제공한다

\section{Acknowledgements}

This study was supported by the grant funded by the Yonsei University Future-leading Research Initiative (2016-220094) and by the Ministry of Education of the Republic of Korea and the National Research Foundation of Korea (NRF2015S1A3A2046711).

\section{Notes}

A part of this article was presented as a poster at the 2015 Annual Conference of the Korean Psychological Association.

\section{Conflict of Interest}

No potential conflict of interest relevant to this article was reported.

\section{References}

\section{In English}

Balaban, M. T., \& Waxman, S. R. (1997). Do words facilitate categorization in 9-month-old infants? Journal of Experimental Child Psychology, 64(1), 3-26. doi:10.1006/ jecp.1996.2332

Baldwin, D. A., Markman, E. M., Bill, B., Desjardins, R. N., Irwin, J. M., \& Tidball, G. (1996). Infants' reliance on a social criterion for establishing word-object relations. Child Development, 67(6), 3135-3153. doi:10.1111/j.14678624.1996.tb01906.x

Beier, J. S., \& Spelke, E. S. (2012). Infants' developing understanding of social gaze. Child Development, 83(2), 486-496. doi:10.1111/j.1467-8624.2011.01702.x

Brooks, R., \& Meltzoff, A. N. (2005). The development of gaze following and its relation to language. Developmental Science, 8(6), 535-543. doi:10.1111/j.1467-7687.2005.00445.x 
Butterworth, G., \& Jarrett, N. (1991). What minds have in common is space: Spatial mechanisms serving joint visual attention in infancy. British Journal of Developmental Psychology, 9(1), 55-72. doi:10.1111/j.2044-835X.1991.tb00862.x

Buresh, J. S., \& Woodward, A. L. (2007). Infants track action goals within and across agents. Cognition, 104(2), 287-314. doi:10.1016/j.cognition.2006.07.001

Cannon, E. N., \& Woodward, A. L. (2012). Infants generate goalbased action predictions. Developmental Science, 15(2), 292298. doi:10.1111/j.1467-7687.2011.01127.x

Carpenter, M., Nagell, K., Tomasello, M., Butterworth, G., \& Moore, C. (1998). Social cognition, joint attention, and communicative competence from 9 to 15 months of age. Monographs of the Society for Research in Child Development, 63(4), i-174. doi:10.2307/1166214

Caza, G. A., \& Knott, A. (2012). Pragmatic bootstrapping: a neural network model of vocabulary acquisition. Language Learning and Development, 8(2), 113-135. doi:10.1080/15475441.2011 .581144

Cooper, R. P., \& Aslin, R. N. (1990). Preference for infant-directed speech in the first month after birth. Child Development, 61(5), 1584-1595. doi:10.1111/j.1467-8624.1990.tb02885.x

Csibra, G. (2003). Teleological and referential understanding of action in infancy. Philosophical Transactions of the Royal Society of London B: Biological Sciences, 358(1431), $447-$ 458. doi:10.1098/rstb.2002.1235

D’Entremont, B., \& Muir, D. (1999). Infant responses to adult happy and sad vocal and facial expressions during face-toface interactions. Infant Behavior and Development, 22(4), 527-539. doi:10.1016/S0163-6383(00)00021-7

Dewar, K., \& Xu, F. (2007). Do 9-month-old infants expect distinct words to refer to kinds? Developmental Psychology, 43(5), 1227-1238. doi:10.1037/0012-1649.43.5.1227

Farroni, T., Csibra, G., Simion, F., \& Johnson, M. H. (2002). Eye contact detection in humans from birth. Proceedings of the National Academy of Sciences, 99(14), 9602-9605. doi:10.1073/pnas.152159999

Gleitman, L. (1990). The structural sources of verb meanings. Language Acquisition, 1(1), 3-55. doi:10.1207/s15327817la0101_2

Graham, S. A., Stock, H., \& Henderson, A. M. (2006). Nineteenmonth-olds' understanding of the conventionality of object labels versus desires. Infancy, 9(3), 341-350. doi:10.1207/ s15327078in0903_5

Grassmann, S., \& Tomasello, M. (2010). Young children follow pointing over words in interpreting acts of reference. Developmental Science, 13(1), 252-263. doi:10.1111/j.1467-7687.2009.00871.x

Haith, M. M., Bergman, T., \& Moore, M. J. (1977). Eye contact and face scanning in early infancy. Science, 198(4319), 853855. doi:10.1126/science.918670

Henderson, A. M., \& Scott, J. C. (2015). She called that thing a mido, but should you call it a mido too? Linguistic experience influences infants' expectations of conventionality. Frontiers in Psychology, 6(332). doi:10.3389/fpsyg.2015.00332

Hornik, R., Risenhoover, N., \& Gunnar, M. (1987). The effects of maternal positive, neutral, and negative affective communications on infant responses to new toys. Child Development, 58(4), 937-944. doi:10.2307/1130534

Jin, K.-S., \& Song, H.-J. (2008, March). Infants' use of words in reasoning about others' goals: Evidence from 12- and 14-month-old infants. Paper presented at the Biennial International Conference on Infant Studies, Vancouver, Canada.

Johnson, S. C., Ok, S. J., \& Luo, Y. (2007). The attribution of attention: 9-month-olds' interpretation of gaze as goal-directed action. Developmental Science, 10(5), 530-537. doi:10.1111/ j.1467-7687.2007.00606.x

Luo, Y. (2010). Do 8-month-old infants consider situational constraints when interpreting others' gaze as goal-directed action? Infancy, 15(4), 392-419. doi:10.1111/j.15327078.2009.00019.x

Martin, A., Onishi, K. H., \& Vouloumanos, A. (2012). Understanding the abstract role of speech in communication at 12 months. Cognition, 123(1), 50-60. doi:10.1016/j.cognition.2011.12.003

Meyer, M., \& Baldwin, D. A. (2013). Pointing as a sociopragmatic cue to particular vs. generic reference. Language Learning and Development, 9(3), 245-265. doi:10.1080/15 475441.2013.753802

Moses, L. J., Baldwin, D. A., Rosicky, J. G., \& Tidball, G. (2001). Evidence for referential understanding in the emotions domain at twelve and eighteen months. Child Development, 72(3), 718-735. doi:10.1111/1467-8624.00311

Phillips, A. T., Wellman, H. M., \& Spelke, E. S. (2002). Infants' ability to connect gaze and emotional expression to intentional action. Cognition, 85(1), 53-78. doi:10.1016/ S0010-0277(02)00073-2

Singh, L., Morgan, J. L., \& Best, C. T. (2002). Infants' listening preferences: Baby talk or happy talk? Infancy, 3(3), 365394. doi:10.1207/S15327078IN0303_5

Song, H.-J., Baillargeon, R., \& Fisher, C. (2014). The development of infants' use of novel verbal information when reasoning about others' actions. PloS One, 9(3), e92387. doi:10.1371/ journal.pone.0092387

Sorce, J. F., Emde, R. N., Campos, J. J., \& Klinnert, M. D. (1985). Maternal emotional signaling: Its effect on the visual cliff behavior of 1-year-olds. Developmental Psychology, 21(1), 195-200. doi:10.1037//0012-1649.21.1.195

Spaepen, E., \& Spelke, E. (2007). Will any doll do? 12-month-olds' reasoning about goal objects. Cognitive Psychology, 54(2), 133-154. doi:10.1016/j.cogpsych.2006.06.001

Sullivan, J., \& Barner, D. (2016). Discourse bootstrapping: 
Preschoolers use linguistic discourse to learn new words. Developmental Science, 19(1), 63-75. doi:10.1111/desc.12289

Thoermer, C., Woodward, A., Sodian, B., Perst, H., \& Kristen, S. (2013). To get the grasp: Seven-month-olds encode and selectively reproduce goal-directed grasping. Journal of Experimental Child Psychology, 116(2), 499-509. doi:10. 1016/j.jecp.2012.12.007

Tomasello, M., Strosberg, R., \& Akhtar, N. (1996). Eighteenmonth-old children learn words in non-ostensive contexts. Journal of Child Language, 23(1), 157-176. doi:10.1017/ S0305000900010138

Walden, T. A., \& Ogan, T. A. (1988). The development of social referencing. Child Development, 59(5), 1230-1240. doi: $10.2307 / 1130486$

Woodward, A. L. (1998). Infants selectively encode the goal object of an agent's reach. Cognition, 69(1), 1-34. doi:10.1016/ S0010-0277(98)00058-4

$\mathrm{Xu}, \mathrm{F}$. (2002). The role of language in acquiring object kind concepts in infancy. Cognition, 85(3), 223-250. doi:10.1016/S00100277(02)00109-9

\section{In Korean}

Kim, M. J., \& Song, H.-J. (2015). Ten-month-olds' ability to use verbal information when understanding others' goal-

directed actions. The Korean Journal of Developmental Psychology, 28(2), 145-160. Retrieved from http://www. dbpia.co.kr/Journal/ArticleDetail/NODE06502390

Lee, Y. M., \& Song, H.-J. (2016). The effects of foreign-language exposure on infants' understanding of conventional properties of language. The Korean Journal of Developmental Psychology, 29(3), 215-229. Retrieved from http://www. dbpia.co.kr/Journal/ArticleDetail/NODE07004339

\section{ORCID}

Youn Mi Cathy Lee

Min Ju Kim

Hyun-joo Song http://orcid.org/0000-0002-6463-1296

http://orcid.org/0000-0001-5878-7350

http://orcid.org/0000-0002-8161-2601

Received December 31, 2016

Revision received February 10, 2017

Accepted February 15, 2017 